\title{
Climate drivers of adult insect activity are conditioned by life history traits
}

\author{
Michael Belitz ${ }^{1}$, Vijay Barve ${ }^{1}$, Joshua Doby ${ }^{1}$, Maggie Hantak $^{1}$, Elise Larsen ${ }^{2}$, Daijiang Li ${ }^{1}$, \\ Jessica Oswald ${ }^{1}$, Neeka Sewnath ${ }^{1}$, Mitchell Walters ${ }^{1}$, Narayani Barve ${ }^{1}$, Kamala Earl ${ }^{1}$, \\ Nicholas Gardner ${ }^{1}$, Robert Guralnick ${ }^{3}$, and Brian Stucky ${ }^{1}$ \\ ${ }^{1}$ Florida Museum of Natural History \\ ${ }^{2}$ Georgetown University \\ ${ }^{3}$ University of Florida
}

March 18, 2021

\begin{abstract}
Insect phenological lability is key for determining which species will adapt under environmental change. However, little is known about when adult insect activity terminates, and overall activity duration. We used community-science and museum specimen data to investigate the effects of climate and urbanization on timing of adult insect activity for 101 species varying in life history traits. We found detritivores and species with aquatic larval stages extend activity periods most rapidly in response to increasing regional temperature. Conversely, species with subterranean larval stages have relatively constant durations regardless of regional temperature. Multivoltine and univoltine species both extended their period of adult activity similarly in warmer conditions. Longer adult durations may represent a general response to warming, but voltinism data in subtropical environments is likely underreported. This effort provides a framework to address drivers of adult insect phenology at continental scales, and a basis for predicting species response to environmental change.
\end{abstract}

\section{Introduction}

Shifts in phenology, i.e., the timing of seasonal biological events, are among the most noticeable impacts of human-caused global change (Cleland et al., 2007; Parmesan, 2007). Numerous studies have shown that recent climate warming advances the timing of spring events, e.g., budburst, breeding of amphibians, and arrival of migrating birds (Parmesan, 2007; While and Uller, 2014; Cohen et al., 2018). Beyond global climate change, large-scale landscape modification can also impact phenology. For example, urbanization has been shown to advance the timing of seasonal events such as plant flowering, in part through the urban heat island effect (reviewed in Neil and $\mathrm{Wu}, 2006$ ). However, more recent work has revealed that urbanization can also delay phenological events, especially in warmer regional climates ( $\mathrm{Li}$ et al., 2019), although the mechanisms driving these delays have yet to be determined. Overall, there is considerable variation in phenological responses to global change both within and among species (Edwards and Richardson, 2004; Thompson and Clark, 2006; Park et al., 2019). If interdependent species differentially respond to humanmediated changes, phenological mismatches may occur with potentially significant, negative demographic consequences (Miller-Rushing et al., 2010; Renner and Zohner, 2018).

Better understanding insect phenological responses is critical given their vast diversity, temperaturedependent developmental timing, and critical role in ecosystems and the services they provide. These services include dung burial, pest control, pollination, and wildlife nutrition and are valued at over $\$ 57$ billion annually in the United States (Losey and Vaughan, 2006). Further, several recent papers have reported dramatic declines in insect populations (Hallmann et al., 2020; Wagner, 2020), potentially due to human-caused land- 
use change, climate change, introduced species, and pollution (Wagner et al., 2021). Phenological shifts may exacerbate losses due to mismatches, but might provide a means to adapt to warmer temperatures and could even lead to overall population growth rates, particularly in species that can successfully add a generation due to extended growing seasons (Kerr et al., 2020).

Most insect phenological studies focus on how climate drives theemergence of insects. In general, warmerthan-average years cause adult insects to emerge earlier (Bartomeus et al., 2011; Roy et al., 2015; VillalobosJiménez and Hassall, 2017). Much less is known about what determines termination or total duration of insect activity (Forrest, 2016). Given extended growing seasons for many plant species (Steltzer and Post, 2009), it might be expected that insects also delay termination of adult insect activities in warmer regions. Longer growing seasons are increasing the number of generations per year (voltinism) of some insects (Altermatt, 2010a; Pöyry et al., 2011), but many species are obligate univoltine across their entire range, including warm regions (Forrest, 2016). For these reasons, life history traits, known to be important in determining insect activity (Diamond et al., 2011; Zografou et al., 2021), may strongly determine adult insect termination. For example, Stemkovski et al. (2020) found that timing of bee emergence was most influenced by climatic variation, but termination of adult bee foraging was better explained by life history traits. Specifically, bee species that nest below ground ended foraging earlier than species nesting above, but bee species that overwinter as prepupae ended foraging later than those that overwinter as pupae (Stemkovski et al., 2020).

Interannual regional climate variation is not the only driver of insect phenology. Urbanization is in general leading to earlier flowering in many plant species due to the urban heat island effect, although these responses may be complex and context dependent (Jochner and Menzel, 2015). Less is known about insects' phenological response to urbanization. The emergence of some insect species appears to be advancing in urbanized areas (Diamond et al., 2015; Chick et al., 2019), but other studies have found no change in phenology across urbanization gradients, despite phenological advances in co-occurring plant species (Seress et al., 2018; Fisogni et al., 2020). The interaction between urbanization and regional temperature can be an important driver of spatial phenology patterns, as urbanization appears to advance plant phenology in cold areas but causes delays in warm areas (Li et al., 2019). Diamond et al. (2014) also demonstrated that the urbanization effect on phenological responses of butterflies depends on regional temperature. This expected interaction between urbanization and temperature remains untested at larger spatial scales and across a broader range of insect groups.

Establishing generalities about determinants of emergence, termination, and duration of adult insect activity is challenging because most phenological research relies on surveys that provide much needed information on species' population abundance but are limited spatially and taxonomically. Recent enormous growth in open and freely accessible and curated community science photographs, such as those available via the iNaturalist platform, are allowing researchers to ask novel phenological questions at greater spatial and taxonomic scales (Li et al., 2021). However, careful data curation and specialized analytical methods must be used to generate biologically meaningful results (Larsen and Shirey, 2021).

Here we use community science generated digital vouchers and digitized museum specimens to investigate how the emergence, termination, and total duration of adult insects varies spatially in response to climate and urbanization. We also examine how such responses differ across species-specific life history traits. We predict strong interactions between traits and key climate predictors. For example, we expect the seasonal activity of insects with thermally buffered larval stages to be less sensitive to variation in temperature than species without thermally buffered larval stages, aligning with a recent study on bees (Stemkovski et al., 2020). We further predict adult duration to vary based on voltinism, with multivoltine species showing stronger responses to temperature than univoltine species. Lastly, we predict adult insect termination to be later and adult duration longer in warmer and urbanized areas, consistent with recent studies in plants (Li et al., 2021).

\section{Methods}

Insect species selection and data acquisition 
We focused on the five most speciose orders with highly distinct adult forms: Coleoptera (beetles), Diptera (flies), Hymenoptera (bees, wasps, ants, and sawflies), Lepidoptera (butterflies and moths), and Trichoptera (caddisflies). We also include the order Odonata (dragonflies and damselflies) and Cicadidae (cicadas), for which nymphs or larvae are visually distinct from adults and occupy infrequently-surveyed habitats (aquatic and subterranean, respectively). A detailed explanation on the species selection protocol can be found in the Supporting Information.

Within these seven higher-level taxonomic groups, we used overall record counts in iNaturalist to select an initial set of candidate species. We limited searching to research-grade observations (verifiable observations with at least two independent species identifications) and included all insect species in focal groups that had at least 1,000 observations within Canada, the United States, and Mexico as of April 8, 2020. Four-hundred and seventy insect species met our search criteria, representing all our focal higher taxonomic groups except for Trichoptera.

We then further filtered to species primarily observed as adults and maintained those for which at least $99.5 \%$ of annotated observations had the life stage annotated as "Adult" by iNaturalist users. Because Lepidoptera are commonly observed as juveniles, we only kept records annotated as adults in our final dataset. Using our final species list, we collected data from GBIF and iDigBio, which aggregate iNaturalist records along with other biological collections. In total, we collected records for 435 species across six insect orders. We limited the temporal scope of our study to the recent years of 2015-2019.

\section{Phenology estimates}

We gridded our study area into $25 \times 25-\mathrm{km}$ equal area cells using the North America Albers Equal Area Conic projection. Community science observations can be biased by organized, public observation events (e.g., iNaturalist's City Nature Challenge) generating an unusually high number of observations that do not reflect the actual seasonal abundance of a species. We therefore filtered our dataset to include only one observation per day of each species in a year, given each cell. Next, the number of observations for each cell-by-year-by-species combination was counted and deemed usable if at least 10 observations were documented. For each unique cell-year-species combination, we estimated the 0.05 and 0.95 sample quantiles using the quantile() function within the stats $\mathrm{R}$ package (R Core Team, 2020) to represent the emergence (first appearance) and termination (last evidence) of adult insect activity. These quantiles are demonstrated to be more robust estimates of phenology than estimating the absolute bounds of a phenophase (Belitz et al. 2020). We calculated the duration of adult insect activity as the difference between the termination and emergence. In total, we used 228,423 records to generate 5,469 emergence, termination, and duration estimates across 626 unique grid cells for 284 species. Over $97 \%$ had a basis of record listed as human observation, indicating the vast majority of the data were generated by community scientists.

\section{Trait data}

We collected trait information from literature and web sources for the 284 included insect species. We focused on traits thought to be relevant to insect phenology, including: 1) voltinism, 2) development type, 3) habitat of immature life stage, 4) diapause stage, and 5) larval diet. We also estimated a categorical trait for the season of adult emergence by calculating the mean emergence for each species. Species that on average emerge as adults prior to the 126th day of the year (DOY) were categorized as spring species, those between the 126th and 176th ( end of June) DOY were categorized as summer species, and the remaining insects were categorized as fall species. Voltinism (broods per year) was categorized as either obligate univoltine, or not obligate univoltine (including species that are only univoltine in part of their range and semi-, parti-, and merovoltine species). Development type was categorized as either hemimetabolous or holometabolous. Habitat of immature life stage was categorized as above ground, freshwater, or underground. Diapause stage was categorized as egg, larva, pupa, adult, none, or migratory. The larval diet was categorized as carnivorous, detritivorous, or herbivorous.

Many of the species that passed initial filters for numbers of observations were missing trait data and were excluded from further analyses (Figure 1). We also removed species that do not diapause or are migratory, 
as these species likely have different physiological responses to temperature and urbanization than the other species. Additionally, eusocial insects were removed, because many can thermoregulate in unique ways (Heinrich, 1972; Jones and Oldroyd, 2006; Menzel and Feldmeyer, 2021). Finally, we removed species that had less than 5 unique year-by-grid cell combinations. After filtering our dataset to match these requirements, we were left with 2,643 estimates of emergence, termination, and duration from 101 species across 412 unique grid cells (Figure 2).

\section{Climate and urbanization data}

We included four climate and one urbanization variable in our modeling framework. The climate variables were year-specific and included mean annual temperature, annual precipitation, temperature seasonality, and precipitation seasonality. We obtained annual mean values of the maximum 2-m air temperature data and annual precipitation values for North America at a 1-km spatial resolution for the five years of our study from Daymet (Thornton et al., 2016a). We generated annual temperature and precipitation seasonality using the monthly maximum temperature and precipitation summaries provided by Daymet at a 1-km spatial resolution (Thornton et al., 2016b). Temperature seasonality was calculated as the standard deviation of the monthly maximum temperature values for the corresponding year, and precipitation seasonality was the coefficient of variation of the monthly precipitation values for the corresponding year.

We used estimated human population density for the year 2020 as a proxy for urbanization and obtained this data from the Center for International Earth Science Information Network, which provides global estimates of population density at a 0.25 degree resolution $(\sim 27-\mathrm{km}$; CIESIN, 2017). Global estimates of human population density are only available on five-year intervals, so we choose to only use the 2020 estimates as a proxy for urbanization given our sampling temporal extent. Year-specific changes in human population density are minimal compared to the variation across space, and therefore should have minimal impact on statistical models.

\section{Statistical analysis}

We used linear mixed models (LMM) to examine the effects of climate, urbanization, and life history traits on the emergence, termination, and duration of adult insect activity across North America. Estimates of emergence, termination, and duration were the response variables, and we included human population density, mean annual temperature, annual precipitation, temperature seasonality, precipitation seasonality as predictor variables along with two, two-way interactions based on previous biological knowledge. The two-way interaction terms tested were: 1) whether the effects of annual temperature changed along a precipitation gradient and 2) whether the impacts of human population density changed along a temperature gradient. Areas with higher human population densities may have more incidental data records, biasing phenological metrics and we controlled for this by including the number of observations as a fixed effect in our initial model. We scaled variables to have a mean of zero and standard deviation (s.d.) of one to ensure comparable model effect sizes across variables. Cell identity and insect species were included as random terms for intercepts, and insect species were included as a random term for the slope of each predictor variable. Next, we used backward model selection using the step function from the R package lmerTest(Kuznetsova et al., 2017). If any variance inflation factor (VIF) was greater than five for a variable in the best model, we removed the correlated variable with lower coefficient and reran our backward selection process.

After selecting the best model with only climate, human population density, and number of observation variables, we added insect traits to our models. We added two-way interaction terms between each trait variable with the climate and human population density variables to examine if adult insect phenology along climate and population density gradients changed for each trait. Backward model selection was performed as described above to reduce model variables and select a best model. Again, if any VIF was greater than five for the variables in the best model, we removed the correlated variable with the lowest coefficient and reran our backward selection process.

LMM can lead to false conclusions and inflated type I error rates if phylogenetic relationships are ignored (Li and Ives, 2017). We therefore generated a subtree from the Open Tree of Life for the 101 insects in 
our analysis using the $\mathrm{R}$ package $\operatorname{rotl}($ Michonneau et al., 2016). Branch lengths were generated by searching the TimeTree of Life database (Kumar et al., 2017) to get the estimated divergence time of each internal node. The branch lengths were then scaled from these ages using the ph_bladj() function from the R package phylocomr (Ooms and Chamberlain, 2019). We used this synthesis phylogeny to fit phylogenetic linear mixed models (PLMM) using a Bayesian framework with the default uninformative INLA priors (Rue et al., 2009). We used the R package $\operatorname{phyr}(\mathrm{Li}$ et al., 2020) to fit our top LMM as PLMM. Our results differed slightly between the PLMM and LMM, and therefore, we present the results based on PLMM in the main text. Results of linear mixed models are included in the supporting information (Supporting Information Tables 1-3). We checked residuals of the top models to ensure models did not have any obvious deviation from model assumptions, including spatial autocorrelations (See Supporting Information for more details and Figure S1 for residuals of the top models). We measured the goodness of fit of our PLMM using the packagerr2 (Ives and $\mathrm{Li}, 2018$ ) to generate partial $\mathrm{R}^{2}$ values (see supporting information for additional details).

\section{Results}

The emergence of adult insect activity is impacted by temperature, precipitation, temperature seasonality, life history traits, and the interactions among these variables (Table 1). Species that diapause as an egg have later emergence dates (approximately 45.7 days) than species that overwinter as adults (Table 1). A one standard deviation (s.d.) increase in temperature $\left(4.77^{\circ} \mathrm{C}\right.$ ) led to earlier emergence of approximately 12.8 days (95\% Bayesian credible intervals (CI) 3.6 - 22.0), but the effects of temperature varied with respect to regional precipitation and human population density values. Compared to areas with high human population density, emergence values are earlier in cool regions with low population density, but later in warm regions with low population density (Figure 3A). Insects in warmer areas emerge earlier than in cool areas, and these phenology shifts are more extreme in wet areas compared to drier areas (Figure 3B). The interaction between temperature and diapause stage, and the interaction between precipitation and voltinism also impacted the emergence of adult insect activity. The emergence of species that diapause as larva or pupa were more sensitive to temperature than species that diapause as adults or eggs (Figure 3C). Univoltine species had earlier emergence in areas with more precipitation, while species that are not univoltine had later emergence in areas with more precipitation (Figure 3D). There was a phylogenetic signal of the random species-specific intercept and the random species-specific slopes of temperature seasonality and precipitation (Supporting Information Figure S2). The partial $\mathrm{R}^{2}$ of our best emergence model was 0.75 (Supporting Information Figure S3).

The top termination model consisted of a set of predictors that included precipitation, temperature seasonality, life-history traits, and the interaction between temperature seasonality and diapause stage (Table 1). A one s.d. increase in precipitation $(324 \mathrm{~mm}$ ) led to a delay in termination of approximately 3 days (95\% CI 1.1 - 4.8). Termination of activity was earlier for species that are first observed in spring or summer compared to species that are first observed as adults in fall (Table 1). Additionally, insect species that diapause as larvae terminate adult activity earlier than insects that diapause in other life stages (-18.4, 95\% CI -35.8 - -0.7; Table 1). The termination of species that diapause as eggs were the most sensitive to temperature seasonality (Figure 4). Species that spend their immature life stage underground had earlier termination than species that spend their immature life stage in freshwater or aboveground. Detritivores had later terminations than herbivores or carnivores. Phylogenetic signal was again apparent for the species-specific random intercept and species-specific random slope of temperature seasonality and precipitation (Supporting Information Figure $\mathrm{S} 2$ ). The partial $\mathrm{R}^{2}$ of our best termination model was 0.58 (Supporting Information Figure S3).

The top model of adult insect duration was predicted by climate, life history traits, and the interaction between temperature and these other variables. Areas with greater temperature seasonality had shorter durations (Table 1). Additionally, areas with high precipitation had longer durations in warm regions but shorter durations in cool regions (Figure 5A). In contrast to species whose immature habitat is above ground or in freshwater, species whose immature habitat is underground were found to have consistent durations, regardless of whether they were in a warm or cool region (Figure 5B). Diapause stage was again an important trait, with insects that diapause as adults having the longest durations. Conversely, the durations of species 
that diapause as larvae were the shortest, 44.8 days shorter than species that diapause as adults (95\% CI 26.1 - 62.7; Table 1). The duration of detritivores was strongly tied to regional temperature, with duration being much longer in warm regions compared to cool regions (Figure 5C). In addition to there being a phylogenetic signal in species-specific intercept and the species-specific slope of temperature, variation in duration was also partially explained by the phylogenetic signal in the species-specific precipitation slope (Supporting Information Figure 2). The partial $\mathrm{R}^{2}$ of our best duration model was 0.75 (Supporting Information Figure 3 ). The number of observations used to estimate the phenometrics was included as a predictor variable in the top duration model, as well as in the top emergence and termination model.

\section{Discussion}

Most studies of insect phenology have focused on regional scales, and the few studies at larger spatial scales have been constrained to species easily identified by trained volunteers such as butterflies in the United Kingdom (e.g., Hodgson et al., 2011; Roy et al., 2015). Here, we leverage rapidly increasing, openly available observation records to achieve the broad phylogenetic sampling necessary for finding commonalities in phenological sensitivity related to climate and life history traits, both important predictors of insect phenology. Our key finding is that timing of adult insect activity is temperature-driven but strongly conditioned by species traits and less-so by phylogenetic relatedness. As we discuss below, these findings provide a basis for prediction of phenological responses in the face of environmental change.

\section{Drivers of adult insect emergence, termination, and duration}

In comparison to other aspects of insect phenology, the drivers of adult emergence are relatively well understood. The emergence of many insect species is controlled by temperature because the growth rate of immature stages increases at warmer temperatures (Gilbert and Raworth, 1996; Hodgson et al., 2011). Life history traits, particularly diapause stage, are also known to be an important predictor of when insects emerge (Scott and Epstein, 1987; Altermatt, 2010b). Our results confirm earlier emergence in warmer areas and in species that diapause as adults.

Less is known about drivers of termination and duration of adult insects. For many insects, photoperiod is likely predictive of activity termination since it is a primary cue in many insects to initiate diapause (Tauber and Tauber, 1976; Denlinger, 2002). Although photoperiod is often the main driver, diapause induction has also been related to temperature, food availability, moisture, and chemical cues (Danks, 2007). Our results also suggest that many factors contribute to the termination of adult activity and indicate that these processes may be linked to temperature seasonality, timing of the first fall freezes, or resource depletion caused for example by drought. In multivoltine insects, we expected longer activity durations in warmer regions, due to the production of additional adult generations in areas with longer growing seasons (Altermatt, 2010a; Zeuss et al., 2017). It is less clear how temperature influences the duration of univoltine insects. Because obligate univoltine species cannot produce additional generations in warmer regions, we expected more consistent activity durations across temperature gradients, regardless of emergence dates. However, we did not find an interaction between temperature and voltinism, suggesting similar temperature-driven increases in duration regardless of voltinism. This surprising result could be explained by multiple mechanisms for extending adult activity, including lengthening timing of activity of cohorts of adults, more generations per season, and reduced adult synchrony of univoltine populations in warm areas. However, this result may be due to our simplistic trait coding system labeling semi-, parti-, and merovoltine species as "not univoltine". While this does not impact our finding of longer activity periods for univoltine species in warmer regions, more finely scored voltinism states may help elucidate trait-mediated phenology responses to temperature. We also note that our understanding of life history traits, particularly voltinism and migratory behavior, is incomplete across broad temperature gradients. Species that are documented in the literature as non-migratory and univoltine may in fact have undescribed migratory patterns (Robinson et al., 2009) or potentially multiple generations in warmer regions that remain unreported.

One of the challenges with understanding phenological sensitivities is that regional contexts may impact not only the strength of sensitivity but also its direction. Li et al. (2019) showed, for example, that urbanization 
shifts from advancing flowering in cold regions to delaying in warmer ones. Here we also find strong evidence of these region-specific contextual effects. One of the clearest examples is that the influence of precipitation and life history traits on insect duration varies with regional temperature. Warm, wet areas demonstrated longer adult insect duration than cooler, wetter regions. This interaction is expected, considering that snow contributes to annual precipitation in cool regions and snowmelt date delays the beginning of activity more than the end (Stemkovski et al., 2020). These regional effects also included life history interactions with temperature. We found that detritivores terminated activity later and had longer durations than carnivores, potentially due to detritus being more available later into the fall compared to green leaf materials or prey items. This effect is especially strong in warm environments, where detritus can accumulate year round.

We also expected a complex interaction between temperature and urbanization, similar to the results of Diamond et al. (2014) for butterflies in Ohio, which documented earlier emergence in cold areas with high human population density and delayed emergence in warmer, more urbanized areas. While we found such an interaction, it was in the opposite direction than expected: insects generally emerged later in cool, urbanized areas and earlier in warm, urbanized areas, in comparison to corresponding rural areas. Due to our species selection protocol, our species list likely overrepresented exploitative species since these are commonly observed. Exploitative butterflies showed smaller delays in first appearance in warm and urbanized areas (Diamond et al., 2014), potentially, in part, explaining our differing results. We encourage future work exploring how urbanization impacts insect phenology and at what spatial scales urbanization influences are most apparent.

\section{Ecological implications}

Our results suggest that adult insects will emerge earlier under climate change scenarios due to warming temperatures, but the termination of insect activity will be less sensitive to changing climates. This may lead to an overall lengthening of insect duration in response to global warming, particularly in areas with high precipitation. Longer insect activity periods may buffer against phenological mismatch of insects interacting with other trophic levels, as long as insect abundance is sufficiently high. However, mounting evidence suggests widespread terrestrial insect declines (van Klink et al., 2020; Wagner et al., 2021; Warren et al., 2021), which raises the threat of reduced ecological services regardless of how much synchrony occurs between interacting species.

One of the fundamental unanswered questions in understanding insect response to global change is which species will thrive - the winners, and which will be most negatively impacted - the losers. Phenology may be a key indicator of winners versus losers given recent work demonstrating that changes in insect population sizes correlate with phenological lability. Some insects may be able to adjust and thrive in warmer environments if additional land use changes are not occurring (Michielini et al., 2021). For example, multivoltine Lepidoptera with early adult emergence in warm years showed increased within- and betweenyear population growth in Britain (Macgregor et al., 2019). Elongated adult activity periods were also the best predictor of increases in relative abundance of Massachusetts butterflies (Michielini et al., 2021).

Our results point to two life history traits that may predict winners and losers in the face of future climate change. Detritivores and insects with larval habitats in freshwater exhibit a stronger response of activity period to temperature than do other insects, indicating these species may be relatively better suited to persist in novel climate scenarios. Conversely, species that have underground larval habitats may be more at risk, as duration for these species remains relatively fixed across temperature gradients. We note that these conclusions must be interpreted with care, as our models are primarily fit across a spatial gradient. Spacefor-time models of ecological change are controversial because ecological processes are often nonstationary (Damgaard, 2019). Still, some empirical studies support these inferences. A recent meta-analysis found broad declines in terrestrial insects but increases in freshwater insect populations (van Klink et al., 2020). No net declines in detritivores were detected across five long term ecological research sites (Crossley et al., 2020), although these results have been questioned (Welti et al., 2020).

Future work and caveats 
Our study is unique in its spatial and taxonomic extent, yet the majority of the species used are in Odonata and Lepidoptera. This is not surprising, since these clades have relatively large body sizes and are easy to see and photograph. In addition to the taxonomic biases in our dataset, the $25 \mathrm{x} 25-\mathrm{km}$ grid cells that were included in our analyses were biased geographically, with most cells occurring in metropolitan areas in the Eastern Temperate Forests ecoregion and along the California Coast. There are noticeable sampling gaps in the Great Plains, North American deserts, and the complex and diverse ecoregions of southern Mexico. Finally, we note that increasing observer effort, measured as the number of observations, did show a significant, albeit relatively weak effect on phenology estimates. Although our modeling framework attempted to control for these effects, care must be taken when fitting estimations using community science datasets. As the amount of available incidental data continues to grow, we expect better spatial, and phylogenetic resolution, albeit with biases still likely, unless concerted efforts are made by community scientists to survey more rural locations (Shirey et al., 2021).

Even if more species-specific phenology estimates can be generated for insects, our full ability to understand drivers of insect phenology will be hampered by the lack of available trait data. We had enough incidental intra-annual observations to generate phenological estimates for 154 species with at least five year-by-cell combinations but could only use 101 species because of missing trait data. This is particularly problematic because our results highlight the importance of life history traits in predicting all aspects of adult insect phenology. Therefore, to better understand how insects will respond to climate change and urbanization, it is imperative that continued effort goes into generating, compiling, and archiving openly available insect life history information (e.g., Middleton-Welling et al., 2020). Improving insect trait knowledge and access will allow researchers to better understand ecological processes using the accelerating accumulation of occurrence and other natural history records. This research showcases a framework to gather and use these resources to answer fundamental questions about the duration of adult activity across broad spatial and phylogenetic scales.

\section{Acknowledgements}

We thank the many iNaturalist users who are recording and identifying insect biodiversity. We also thank those who have collected, curated, and digitized insect specimen records. MWB was partially supported by a University of Florida Biodiversity Institute (UFBI) fellowship. CJ Campbell provided valuable feedback. No direct funding supported this study, but MWB, EAL, and RPG developed phenological tools and concepts used in this study that were supported by the National Science Foundation DEB \# 1703048 and DEB \# 1702664 .

\section{References}

Altermatt, F. (2010a). Climatic warming increases voltinism in European butterflies and moths.Proc Biol Sci277, 1281-1287. doi:10.1098/rspb.2009.1910.

Altermatt, F. (2010b). Tell me what you eat and I'll tell you when you fly: diet can predict phenological changes in response to climate change. Ecology Letters 13, 1475-1484. doi:https://doi.org/10.1111/j.14610248.2010.01534.x.

Bartomeus, I., Ascher, J. S., Wagner, D., Danforth, B. N., Colla, S., Kornbluth, S., et al. (2011). Climateassociated phenological advances in bee pollinators and bee-pollinated plants. PNAS 108, 20645-20649. doi:10.1073/pnas.1115559108.

Belitz, M. W. (2021). InsectDuration: Code for Manuscript Submission (Version v1.0). Zenodo . http://doi.org/10.5281/zenodo.4574261

Belitz, M. W., Larsen, E. A., Ries, L., and Guralnick, R. P. (2020). The accuracy of phenology estimators for use with sparsely sampled presence-only observations. Methods in Ecology and Evolution , 11 (10), 1273-1285. doi:10.1111/2041-210X.13448

Center for International Earth Science Information Network-CIESIN-Columbia University (2017). Gridded 
population of the world, Version 4 (GPWv4): Population Density, Revision 11. doi:10.7927/H49C6VHW.

Chick, L. D., Strickler, S. A., Perez, A., Martin, R. A., and Diamond, S. E. (2019). Urban heat islands advance the timing of reproduction in a social insect. Journal of Thermal Biology 80, 119-125. doi:10.1016/j.jtherbio.2019.01.004.

Cleland, E. E., Chuine, I., Menzel, A., Mooney, H. A., and Schwartz, M. D. (2007). Shifting plant phenology in response to global change. Trends in Ecology \& Evolution 22, 357-365. doi:10.1016/j.tree.2007.04.003.

Cohen, J. M., Lajeunesse, M. J., and Rohr, J. R. (2018). A global synthesis of animal phenological responses to climate change. Nature Climate Change8, 224-228. doi:10.1038/s41558-018-0067-3.

Crossley, M. S., Meier, A. R., Baldwin, E. M., Berry, L. L., Crenshaw, L. C., Hartman, G. L., et al. (2020). No net insect abundance and diversity declines across US Long Term Ecological Research sites. Nature Ecology ES Evolution 4, 1368-1376. doi:10.1038/s41559-020-1269-4.

Damgaard, C. (2019). A Critique of the Space-for-Time Substitution Practice in Community Ecology. Trends in Ecology \& Evolution 34, 416-421. doi:10.1016/j.tree.2019.01.013.

Danks, H. V. (2007). The elements of seasonal adaptations in insects. The Canadian Entomologist , 139 (1), 1-44. doi.org/10.4039/n06-048

Denlinger, D. L. (2002). Regulation of diapause. Annual review of entomology 47, 93-122.

Diamond, S. E., Dunn, R. R., Frank, S. D., Haddad, N. M., and Martin, R. A. (2015). Shared and unique responses of insects to the interaction of urbanization and background climate. Current Opinion in Insect Science 11, 71-77. doi:10.1016/j.cois.2015.10.001.

Diamond, S. E., Frame, A. M., Martin, R. A., and Buckley, L. B. (2011). Species' traits predict phenological responses to climate change in butterflies. Ecology92, 1005-1012. doi:https://doi.org/10.1890/10-1594.1.

Diamond, S. E., Cayton, H., Wepprich, T., Jenkins, C. N., Dunn, R. R., Haddad, N. M., et al. (2014). Unexpected phenological responses of butterflies to the interaction of urbanization and geographic temperature. Ecology95, 2613-2621. doi:10.1890/13-1848.1.

Edwards, M., and Richardson, A. J. (2004). Impact of climate change on marine pelagic phenology and trophic mismatch. Nature 430, 881-884. doi:10.1038/nature02808.

Fisogni, A., Hautekeete, N., Piquot, Y., Brun, M., Vanappelghem, C., Michez, D., et al. (2020). Urbanization drives an early spring for plants but not for pollinators. Oikos 129, 1681-1691. doi:https://doi.org/10.1111/oik.07274.

Forrest, J. R. (2016). Complex responses of insect phenology to climate change. Current Opinion in Insect Science 17, 49-54. doi:10.1016/j.cois.2016.07.002.

GBIF. (2020a). GBIF Occurrence download. https://doi.org/10.15468/dl.6y59tz

GBIF. (2020b). GBIF Occurrence download. https://doi.org/10.15468/dl.vkunmd

GBIF. (2020c). GBIF Occurrence download. https://doi.org/10.15468/dl.yz7uuv

GBIF. (2020d). GBIF Occurrence download. https://doi.org/10.15468/dl.n5f8hv

GBIF. (2020e). GBIF Occurrence download. https://doi.org/10.15468/dl.jp9fd3

Gilbert, N., and Raworth, D. A. (1996). Forum: Insects and temperature - A general theory. The Canadian Entomologist 128, 1-13. doi:10.4039/Ent1281-1.

Hallmann, C. A., Zeegers, T., Klink, R. van, Vermeulen, R., Wielink, P. van, Spijkers, H., et al. (2020). Declining abundance of beetles, moths and caddisflies in the Netherlands. Insect Conservation and Diversity 13, 127-139. doi:https://doi.org/10.1111/icad.12377. 
Heinrich, B. (1972). Physiology of Brood Incubation in the Bumblebee Queen, Bombus vosnesenskii. Nature 239, 223-225. doi:10.1038/239223a0.

Hodgson, J. A., Thomas, C. D., Oliver, T. H., Anderson, B. J., Brereton, T. M., and Crone, E. E. (2011). Predicting insect phenology across space and time. Global Change Biology 17, 1289-1300. doi:10.1111/j.13652486.2010.02308.x.

Ives, A. R., and Li, D. (2018). 'rr2': An R package to calculate R2s for regression models. Journal of Open Source Software 3, 1028. doi:10.21105/joss.01028.

Jochner, S., and Menzel, A. (2015). Urban phenological studies - Past, present, future.Environmental Pollution 203, 250-261. doi:10.1016/j.envpol.2015.01.003.

Jones, J. C., and Oldroyd, B. P. (2006). "Nest Thermoregulation in Social Insects," inAdvances in Insect Physiology, ed. S. J. Simpson (Academic Press), 153-191. doi:10.1016/S0065-2806(06)33003-2.

Kerr, N. Z., Wepprich, T., Grevstad, F. S., Dopman, E. B., Chew, F. S., and Crone, E. E. (2020). Developmental trap or demographic bonanza? Opposing consequences of earlier phenology in a changing climate for a multivoltine butterfly. Global Change Biology 26, 2014-2027. doi:10.1111/gcb.14959.

Kumar, S., Stecher, G., Suleski, M., and Hedges, S. B. (2017). TimeTree: A Resource for Timelines, Timetrees, and Divergence Times. Mol Biol Evol 34, 1812-1819. doi:10.1093/molbev/msx116.

Kuznetsova, A., Brockhoff, P. B., and Christensen, R. H. B. (2017). lmerTest Package: Tests in Linear Mixed Effects Models. Journal of Statistical Software 82, 1-26. doi:10.18637/jss.v082.i13.

Larsen, E., and Shirey, V. (2021). Method matters: pitfalls in analyzing phenology from occurrence records. Authorea. doi:10.22541/au.161001475.56669645/v1.

Li, D., Barve, N., Brenskelle, L., Earl, K., Barve, V., Belitz, M. W., et al. (2021). Climate, urbanization, and species traits interactively drive flowering duration. Global Change Biology 27, 892-903. doi:https://doi.org/10.1111/gcb.15461.

Li, D., Dinnage, R., Nell, L. A., Helmus, M. R., and Ives, A. R. (2020). phyr: an R package for phylogenetic species-distribution modelling in ecological communities. Methods in Ecology and Evolution 11, 1455-1463.

Li, D., and Ives, A. R. (2017). The statistical need to include phylogeny in trait-based analyses of community composition. Methods in Ecology and Evolution 8, 1192-1199. doi:https://doi.org/10.1111/2041210X.12767.

Li, D., Stucky, B. J., Deck, J., Baiser, B., and Guralnick, R. P. (2019). The effect of urbanization on plant phenology depends on regional temperature. Nature Ecology \&6 Evolution 3, 1661-1667. doi:10.1038/s41559019-1004-1.

Losey, J. E., and Vaughan, M. (2006). The Economic Value of Ecological Services Provided by Insects. BioScience 56, 311-323. doi:10.1641/0006-3568(2006)56[311:TEVOES]2.0.CO;2.

Macgregor, C. J., Thomas, C. D., Roy, D. B., Beaumont, M. A., Bell, J. R., Brereton, T., et al. (2019). Climate-induced phenology shifts linked to range expansions in species with multiple reproductive cycles per year.Nature Communications 10, 4455. doi:10.1038/s41467-019-12479-w.

Menzel, F., and Feldmeyer, B. (2021). How does climate change affect social insects? Current Opinion in Insect Science. doi:10.1016/j.cois.2021.01.005.

Michielini, J. P., Dopman, E. B., and Crone, E. E. (2021). Changes in flight period predict trends in abundance of Massachusetts butterflies. Ecology Letters24, 249-257. doi:https://doi.org/10.1111/ele.13637.

Michonneau, F., Brown, J. W., and Winter, D. J. (2016). rotl: an R package to interact with the Open Tree of Life data. Methods in Ecology and Evolution 7, 1476-1481. doi:10.1111/2041-210X.12593. 
Middleton-Welling, J., Dapporto, L., Garcia-Barros, E., Wiemers, M., Nowicki, P., Plazio, E., et al. (2020). A new comprehensive trait database of European and Maghreb butterflies, Papilionoidea. Scientific Data 7, 351. doi:10.1038/s41597-020-00697-7.

Miller-Rushing, A. J., Hoye, T. T., Inouye, D. W., and Post, E. (2010). The effects of phenological mismatches on demography. Philos Trans R Soc Lond B Biol Sci 365, 3177-3186. doi:10.1098/rstb.2010.0148.

Neil, K., and Wu, J. (2006). Effects of urbanization on plant flowering phenology: A review.Urban Ecosyst 9, 243-257. doi:10.1007/s11252-006-9354-2.

Ooms, J., and Chamberlain, S. (2019). phylocomr: Interface to "Phylocom."Available at: https://CRAN.Rproject.org $/$ package $=$ phylocomr.

Park, D. S., Breckheimer, I., Williams, A. C., Law, E., Ellison, A. M., and Davis, C. C. (2019). Herbarium specimens reveal substantial and unexpected variation in phenological sensitivity across the eastern United States.Phil. Trans. R. Soc. B 374, 20170394. doi:10.1098/rstb.2017.0394.

Parmesan, C. (2007). Influences of species, latitudes and methodologies on estimates of phenological response to global warming. Global Change Biology13, 1860-1872. doi:10.1111/j.1365-2486.2007.01404.x.

Poyry, J., Leinonen, R., Soderman, G., Nieminen, M., Heikkinen, R. K., and Carter, T. R. (2011). Climateinduced increase of moth multivoltinism in boreal regions. Global Ecology and Biogeography 20, 289-298. doi:https://doi.org/10.1111/j.1466-8238.2010.00597.x.

R Core Team. (2020). R: A language and environment for statistical computing. Version 4.0.0 "Arbor Day". Vienna, Austria: R Foundation for Statistical Computing.

Renner, S. S., and Zohner, C. M. (2018). Climate Change and Phenological Mismatch in Trophic Interactions Among Plants, Insects, and Vertebrates.Annual Review of Ecology, Evolution, and Systematics 49, 165-182. doi:10.1146/annurev-ecolsys-110617-062535.

Robinson, R. A., Crick, H. Q., Learmonth, J. A., Maclean, I. M., Thomas, C. D., Bairlein, F., et al. (2009). Travelling through a warming world: climate change and migratory species. Endangered species research 7 , 87-99.

Roy, D. B., Oliver, T. H., Botham, M. S., Beckmann, B., Brereton, T., Dennis, R. L. H., et al. (2015). Similarities in butterfly emergence dates among populations suggest local adaptation to climate. Global Change Biology 21, 3313-3322. doi:10.1111/gcb.12920.

Rue, H., Martino, S., and Chopin, N. (2009). Approximate Bayesian inference for latent Gaussian models by using integrated nested Laplace approximations. Journal of the Royal Statistical Society: Series B (Statistical Methodology) 71, 319-392. doi:10.1111/j.1467-9868.2008.00700.x.

Scott, J. A., and Epstein, M. E. (1987). Factors affecting phenology in a temperate insect community. American Midland Naturalist, 103-118.

Seress, G., Hammer, T., Bokony, V., Vincze, E., Preiszner, B., Pipoly, I., et al. (2018). Impact of urbanization on abundance and phenology of caterpillars and consequences for breeding in an insectivorous bird. Ecological Applications 28, 1143-1156. doi:10.1002/eap.1730.

Shirey, V., Belitz, M. W., Barve, V., and Guralnick, R. (2021). A complete inventory of North American butterfly occurrence data: narrowing data gaps, but increasing bias. Ecography n/a. doi:https://doi.org/10.1111/ecog.05396.

Steltzer, H., and Post, E. (2009). Seasons and Life Cycles. Science 324, 886-887. doi:10.1126/science.1171542.

Stemkovski, M., Pearse, W. D., Griffin, S. R., Pardee, G. L., Gibbs, J., Griswold, T., et al. (2020). Bee phenology is predicted by climatic variation and functional traits. Ecology Letters 23, 1589-1598. 
doi:https://doi.org/10.1111/ele.13583.

Tauber, M. J., and Tauber, C. A. (1976). Insect seasonality: diapause maintenance, termination, and postdiapause development. Annual review of entomology 21, 81-107.

Thompson, R., and Clark, R. M. (2006). Spatio-temporal modelling and assessment of within-species phenological variability using thermal time methods. Int $J$ Biometeorol 50, 312-322. doi:10.1007/s00484-005$0017-4$.

Thornton, M.M., Thornton, P.E., Wei, Y., Mayer, B.W., Cook, R.B., and Vose, R.S. (2016a). Daymet: Annual Climate Summaries on a 1-km Grid for North America, Version 3. ORNL DAAC, Oak Ridge, Tennessee, USA. https://doi.org/10.3334/ORNLDAAC/1343

Thornton, M.M., Thornton, P.E., Wei, Y., Mayer, B.W., Cook, R.B., and Vose, R.S. (2016b). Daymet: Monthly Climate Summaries on a 1-km Grid for North America, Version 3. ORNL DAAC, Oak Ridge, Tennessee, USA. https://doi.org/10.3334/ORNLDAAC/1345

van Klink, R., Bowler, D. E., Gongalsky, K. B., Swengel, A. B., Gentile, A., and Chase, J. M. (2020). Metaanalysis reveals declines in terrestrial but increases in freshwater insect abundances. Science 368, 417-420. doi:10.1126/science.aax9931.

Villalobos-Jimenez, G., and Hassall, C. (2017). Effects of the urban heat island on the phenology of Odonata in London, UK. Int J Biometeorol 61, 1337-1346. doi:10.1007/s00484-017-1311-7.

Wagner, D. L. (2020). Insect Declines in the Anthropocene. Annual Review of Entomology65, 457-480. doi:10.1146/annurev-ento-011019-025151.

Wagner, D. L., Grames, E. M., Forister, M. L., Berenbaum, M. R., and Stopak, D. (2021). Insect decline in the Anthropocene: Death by a thousand cuts. PNAS 118. doi:10.1073/pnas.2023989118.

Warren, M. S., Maes, D., Swaay, C. A. M. van, Goffart, P., Dyck, H. V., Bourn, N. A. D., et al. (2021). The decline of butterflies in Europe: Problems, significance, and possible solutions. PNAS 118. doi:10.1073/pnas.2002551117.

Welti, E., Joern, A., Lightfoot, D. C., Record, S., Rodenhouse, N., Stanley, E. H., et al. (2020). Metaanalyses of insect temporal trends must account for the complex sampling histories inherent to many longterm monitoring efforts.

While, G. M., and Uller, T. (2014). Quo vadis amphibia? Global warming and breeding phenology in frogs, toads and salamanders. Ecography 37, 921-929. doi:https://doi.org/10.1111/ecog.00521.

Zeuss, D., Brunzel, S., and Brandl, R. (2017). Environmental drivers of voltinism and body size in insect assemblages across Europe. Global Ecology and Biogeography 26, 154-165. doi:https://doi.org/10.1111/geb.12525.

Zografou, K., Swartz, M. T., Adamidis, G. C., Tilden, V. P., McKinney, E. N., and Sewall, B. J. (2021). Species traits affect phenological responses to climate change in a butterfly community. Scientific Reports 11, 3283. doi:10.1038/s41598-021-82723-1.

\section{Tables}

Table 1. Fixed effects coefficients for top emergence, termination, and duration models. Bolding denotes coefficients whose $95 \%$ Bayesian credible interval does not include zero.

\begin{tabular}{|c|c|c|c|}
\hline Term & Emergence & Termination & Duration \\
\hline (Intercept) & $109.0(94.1-123.8)$ & $277.3(247.9-306.4)$ & $147.6(119.6-174.8)$ \\
\hline temp & $-12.8(-22.0--3.6)$ & & $9.3(-8.0-26.6)$ \\
\hline
\end{tabular}




\begin{tabular}{|c|c|c|c|}
\hline Term & Emergence & Termination & Duration \\
\hline prec & $3.3(0.9-5.7)$ & $2.9(1.1-4.8)$ & $0.6(-1.8-3.1)$ \\
\hline temp_seas & $6.0(2.5-9.4)$ & $-5.2(-13.1-2.7)$ & $-17.3(-21.5--13.2)$ \\
\hline diapause.stageEgg & $45.7(24.8-66.2)$ & $-16.4(-37.5-5.0)$ & $-44.6(-65.6-22.7)$ \\
\hline diapause.stageLarvae & $31.2(14.0-48.3)$ & $-18.4(-35.8--0.7)$ & $-44.8(-62.7-26.1)$ \\
\hline diapause.stagePupae & $38.2(20.0-56.7)$ & $-2.2(-21.0-17.0)$ & $-33.2(-51.8--14.1)$ \\
\hline flightsUnivoltine & $6.9-(-3.7-17.5)$ & & \\
\hline seasSpring & & $-37.1(-50.7-.23 .3)$ & \\
\hline seasSummer & & $-24.4(-35.5--13.3)$ & \\
\hline immature.habitatFreshwater & & $15.3(-20.1-50.7)$ & $4.6(-29.0-38.2)$ \\
\hline immature.habitatUnderground & & $-26.9(-47.0--6.6)$ & $-31.5(-52.2--10.5)$ \\
\hline larval.dietDetritivorous & & $37.8(6.02-69.0)$ & $35.4(2.1-68.1)$ \\
\hline larval.dietHerbivorous & & $14.6(-8.6-37.6)$ & $-1.8(-25.6-21.8)$ \\
\hline temp:prec & $-2.6(-4.5--0.7)$ & & $3.1(0.6-5.6)$ \\
\hline temp:pop & $-2.2(-4.3--0.1)$ & & \\
\hline temp:diapause.stageEgg & $-5.1(-16.6-6.2)$ & & \\
\hline temp:diapause.stageLarvae & $-9.3(-18.7-0.2)$ & & \\
\hline temp:diapause.stagePupae & $-12.7(-23.0--2.5)$ & & \\
\hline prec:flightsUnivoltine & $-5.0(-9.8--0.2)$ & & \\
\hline temp_seas:diapause.stageEgg & & $-15.1(-27.0-3.2)$ & \\
\hline temp_seas:diapause.stageLarvae & & $-7.8(-16.6-0.8)$ & \\
\hline temp_seas:diapause.stagePupae & & $-2.6(-12.1-6.8)$ & \\
\hline temp:larval.dietDetritivorous & & & $29.0(6.3-51.5)$ \\
\hline temp:larval.dietHerbivorous & & & $6.1(-11.0-23.1)$ \\
\hline temp:immature.habitatFreshwater & & & $12.0(-10.4-34.5)$ \\
\hline temp:immature.habitatUnderground & & & $-13.1(-26.8-0.9)$ \\
\hline numObs & $-3.6(-4.5--2.8)$ & $4.5(3.5-5.4)$ & $8.1(7.0-9.3)$ \\
\hline
\end{tabular}

\section{Figures}



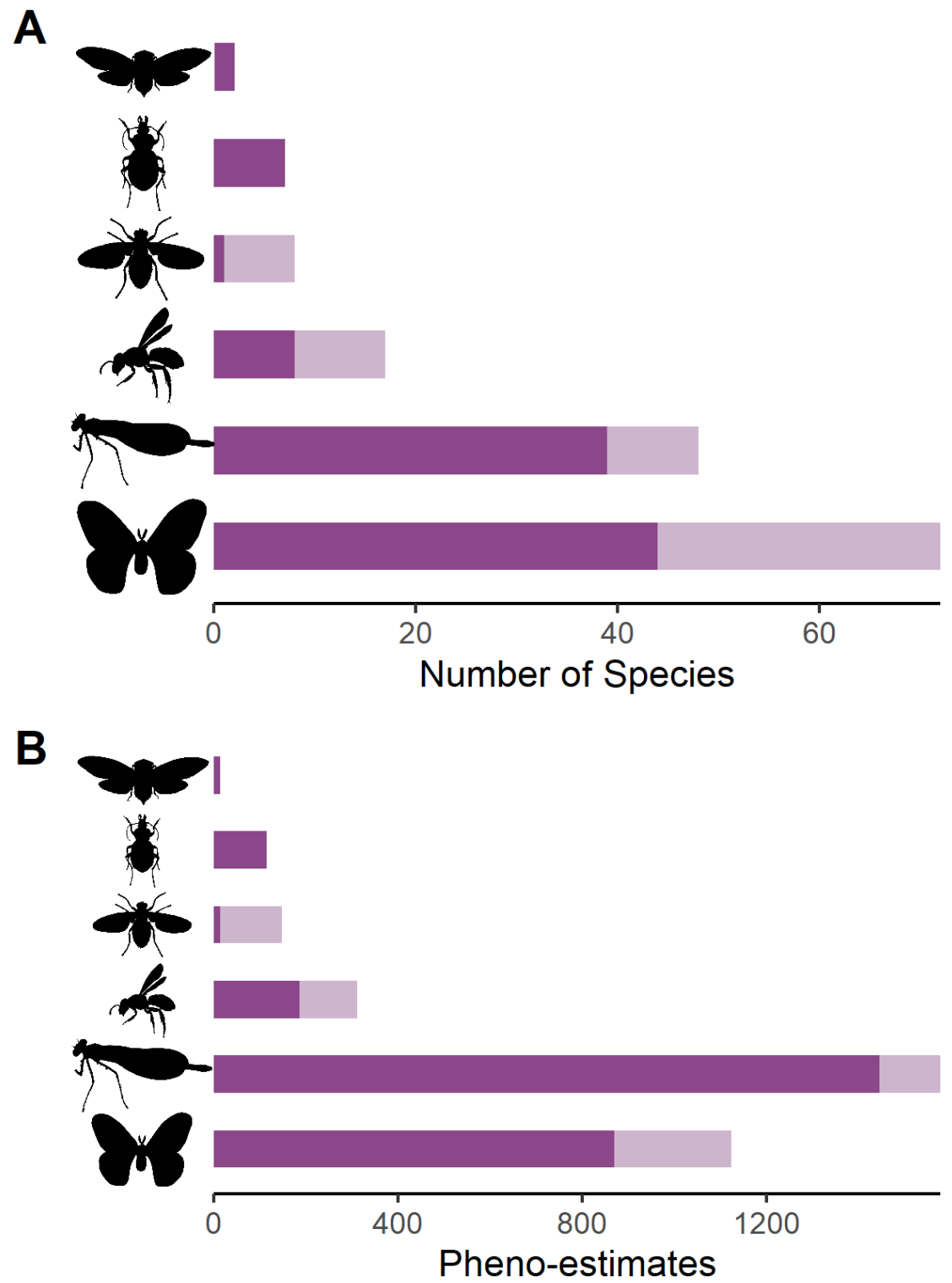

Included Yes No

Figure 1. Number of study species (A) and number of phenology estimates (B) included in or excluded from our modeling framework per taxonomic group (Cicadidae, Coleoptera, Diptera, Hymenoptera, Odonata, and Lepidoptera in top to bottom order shown above). The same species could contribute multiple phenology estimates to the model by having enough records to generate estimates across multiple cells and years. Dark purple indicates the number of species or phenology estimates included in the modeling framework. Light purple indicates species or phenology estimates with enough phenology observations $(>1,000$ iNaturalist observations and available in at least five year-by-cell combinations) that were removed from the analyses because of missing trait data. Counts do not include species that were eusocial, migratory, or do not diapause, as these were not included in our analyses. Silhouettes of Coleoptera (vectorization by T. Michael Keesey; 
photography by Thorsten Assmann, Jörn Buse, Claudia Drees, Ariel-Leib-Leonid Friedman, Tal Levanony, Andrea Matern, Anika Timm, and David W. Wrase), Hymenoptera (vectorization by Melissa Broussard), Odonata (vectorization by Maxime Dahirel), and Lepidoptera (vectorization by Mali'o Kodis, photograph by Jim Vargo) were downloaded from www.phylopic.org. NS generated the Diptera and cicada silhouettes.

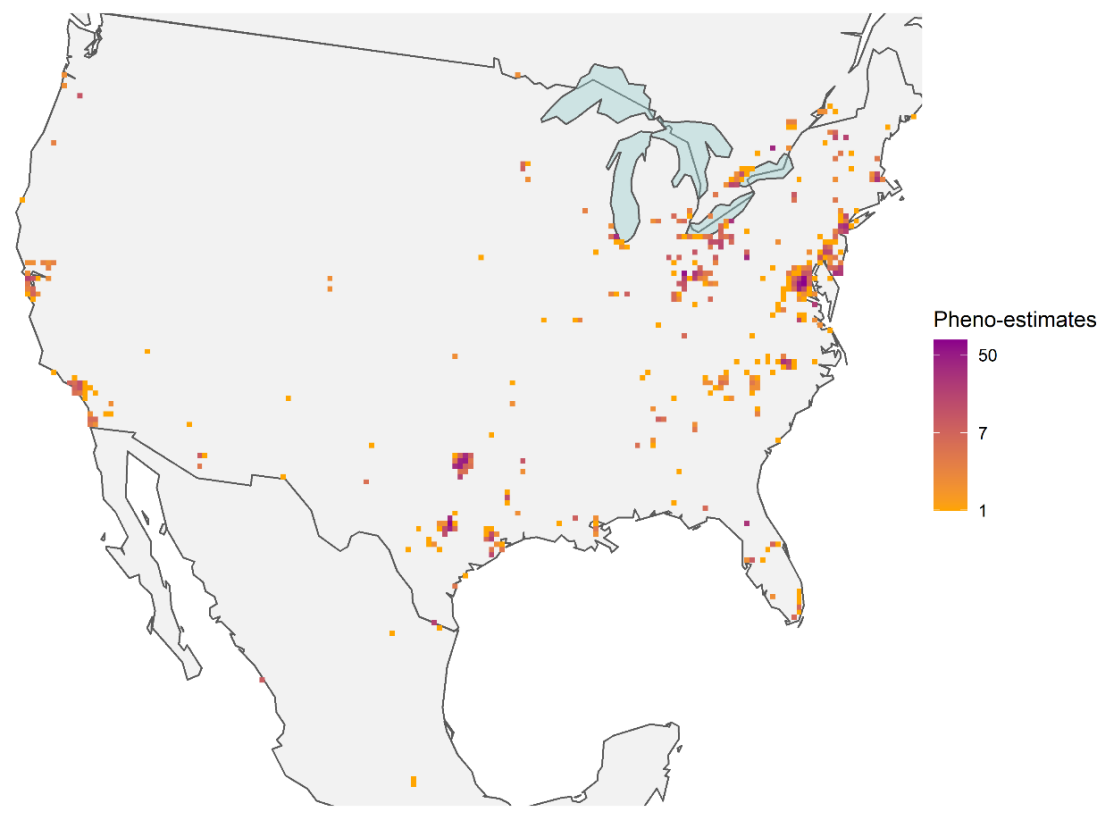

Figure 2. Locations of $25 \times 25-\mathrm{km}$ cells with at least one species-by-year combination with enough data to produce phenology estimates of emergence, termination, and duration. Number of species-year combinations are represented by the color of the cell.
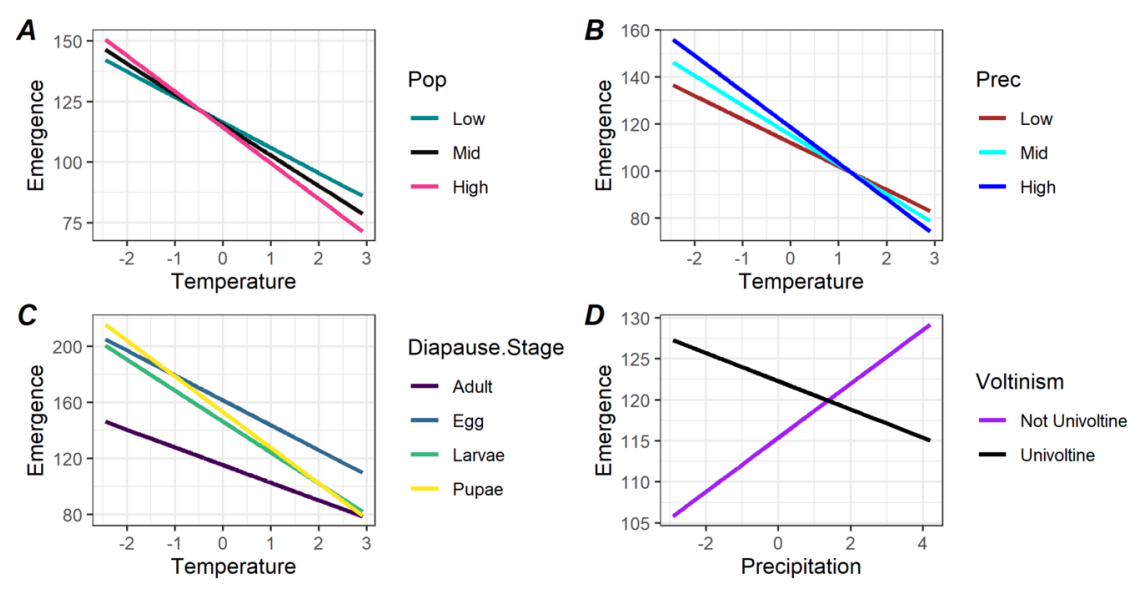

Figure. 3 Two-way interactions included in the top model predicting emergence of adult insect activity. Overall, adult emergence of adult insect activity was earlier in warmer areas and was even earlier in warm areas with high human population densities (A). High precipitation led to earlier emergence in warm areas, but delayed emergence in cool areas (B). The sensitivity of insect emergence to temperature differs depending on what life stage an insect enters diapauses $(\mathrm{C})$. Emergence was earlier for univoltine species in areas with 
high precipitation compared to species that are not univoltine (D). Low, mid, and high population density and precipitation values represent values that are one s.d. above the mean, at the mean, or one s.d. below the mean.

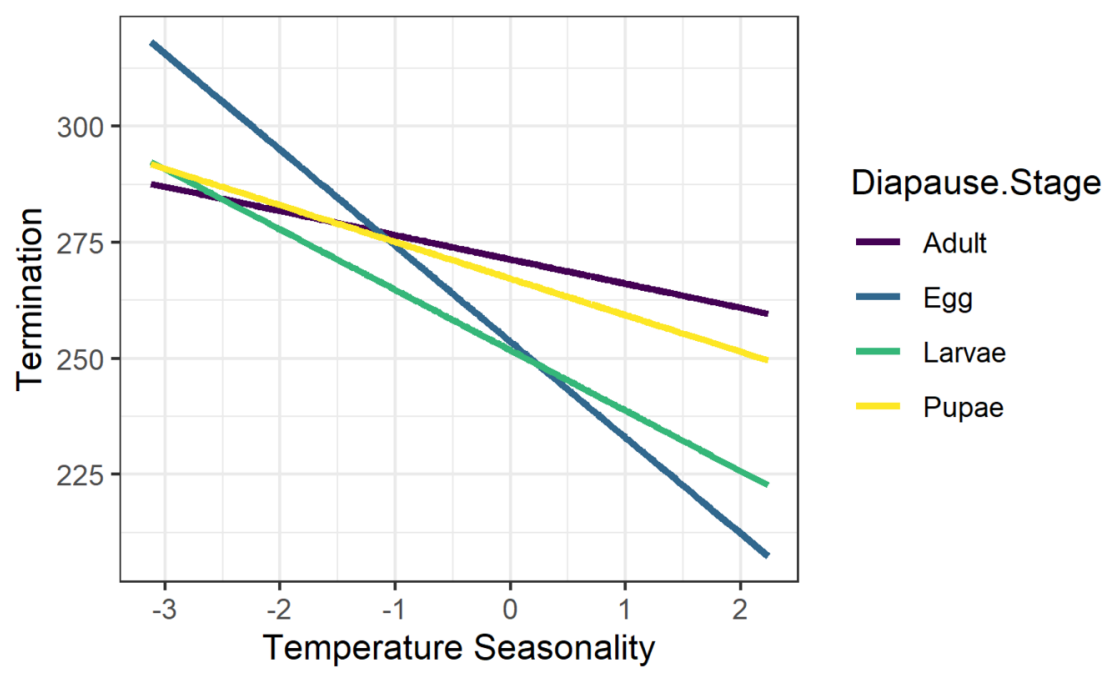

Figure 4. Two-way interaction included in the top model predicting termination of adult insect activity. Termination of adult insect activity was more sensitive in detritivorous insects.

$A$

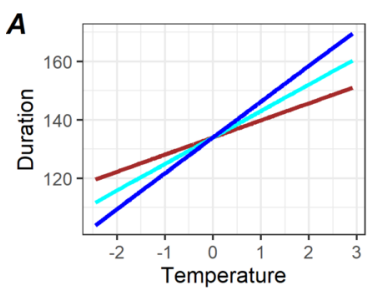

C

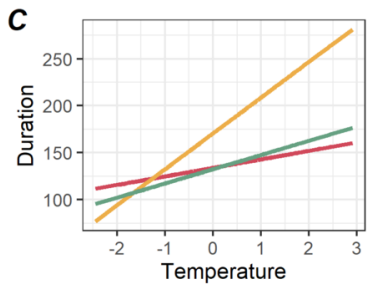

B

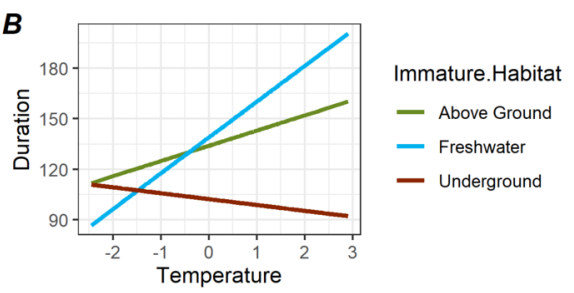

Figure 5. Two-way interactions included in the top model predicting duration of adult insect activity. Insects were active longer in warm areas, especially warm areas with high (one s.d. above the mean) precipitation (A). Species with immature habitats that are underground had relatively constant durations regardless of the regional temperature (B). Detritivores had durations that were most sensitive to temperature (C). 